DOI: 10.12957/demetra.2018.30699

\title{
Alimentos orgânicos e/ou agroecológicos na alimentação escolar em municípios do Rio Grande do Sul, Brasil
}

\section{Organic and/or agro-ecological foods in school meals in municipalities in Rio Grande do Sul, Brazil}

Letiane de Souza Machado

Fernanda Camboim Rockett ${ }^{2}$

Gabriela Cheuiche Pires ${ }^{2}$

Rafaela da Silveira Corrêa ${ }^{2,3}$

Ana Beatriz Almeida de Oliveira ${ }^{4}$

' Universidade Federal do Rio Grande do Sul, Faculdade de Medicina, Departamento de Nutrição. Porto Alegre, RS, Brasil.

${ }^{2}$ Universidade Federal do Rio Grande do Sul, Faculdade de Medicina, Centro Colaborador em Alimentação e Nutrição do Escolar. Porto Alegre, RS, Brasil.

${ }^{3}$ Centro Universitário Ritter dos Reis, Curso de Nutrição. Porto Alegre, RS, Brasil.

${ }^{4}$ Universidade Federal do Rio Grande do Sul, Faculdade de Medicina, Departamento de Nutrição, Centro de Estudos em Alimentação e Nutrição - Hospital de Clínicas de Porto Alegre. Porto Alegre, RS, Brasil.

Correspondência / Correspondence Letiane de Souza Machado E-mail: letianemach@gmail.com

\section{Resumo}

Objetivo: Descrever a aquisição de alimentos orgânicos e/ou agroecológicos para o Programa Nacional de Alimentação Escolar nos municípios do estado do Rio Grande do Sul, Brasil. Metodologia: Estudo transversal, com envio de questionário eletrônico aos 497 municípios do estado, que contemplava: se houve compra de orgânicos e/ou agroecológicos em 2014, principais dificuldades, fatores que influenciaram a escolha, certificação e os alimentos adquiridos. Resultados: Foram obtidas respostas de 362 municípios, sendo que destes, 94 (26,0\%) referiram comprar produtos orgânicos e/ou agroecológicos, o que caracteriza $18,9 \%$ do total de municípios do estado. As principais dificuldades apontadas para a compra desses alimentos foram a baixa quantidade $(54,4 \% ; n=197)$ e variedade $(51,9 \% ; n=188)$; as principais motivações foram, de forma geral, centradas na preocupação com a saúde e o meio ambiente, relatadas por mais de $60 \%$ dos municípios. Destes, 60,6\% $(\mathrm{n}=57)$ relataram que os produtos não tinham certificação ou a desconheciam. Os produtos mais adquiridos foram: alface, laranja e repolho. Conclusão: Embora com percentuais baixos, alimentos orgânicos e/ou agroecológicos estão sendo incluídos na alimentação escolar do estado. Há necessidade de articulação entre responsáveis técnicos, agricultores familiares e demais envolvidos para que essa prática seja desenvolvida e efetivada.

Palavras-chave: Alimentação Escolar. Segurança Alimentar e Nutricional. Alimentos Orgânicos. 


\section{Abstract}

Objectives: Describe the insertion of organic foods for The Brazilian School Feeding Program in the municipalities of Rio Grande do Sul state, Brazil. Methods: Cross-sectional study, with electronic questionnaire sent to 497 municipalities in the state, which included: whether there has been buying organic in 2014, main difficulties, factors that influenced the choice, certification and purchased food. Results: Responses were obtained from 362 municipalities, and of these, $94(26.0 \%)$ reported buying organic products, which represent $18.9 \%$ of all municipalities in the state. The main difficulties identified for the purchase of these foods were low amount $(54.4 \% ; \mathrm{n}=197)$ and variety $(51.9 \% ; \mathrm{n}=188)$; the main motivations were, in general, centered on the concern with health and the environment, reported by more than $60 \%$ of the municipalities. These municipalities, $60.6 \%(\mathrm{n}=57)$ reported that the products had no certification or were unaware. The most purchased products were lettuce, oranges and cabbage. Conclusion: Although low percentage, organic foods are being included in the school feeding in the state. There is a need for articulation between technical managers, farmers and other stakeholders so that this practice can be developed and effective.

Keywords: School Feeding. Food and Nutrition Security. Organic Food.

\section{Introdução}

Os alimentos orgânicos são conceituados como alimentos in natura ou processados livres de agrotóxicos, oriundos de um sistema orgânico de produção agropecuária e/ou industrial que promove a saúde do solo, dos ecossistemas e das pessoas. ${ }^{1,2}$ Já a agroecologia é uma ciência desenvolvida em contraposição ao agronegócio, dedicada ao estudo amplo das relações produtivas entre homem e natureza, como a sustentabilidade ecológica, econômica, social, cultural, política e ética. Baseia-se na pequena propriedade, na mão de obra familiar e em sistemas produtivos complexos adaptados às condições locais e regionais de produção de alimentos. ${ }^{3,4}$ Assim, apesar de os conceitos de agroecologia e agricultura orgânica não serem sinônimos, ambos são livres de agrotóxicos e estão relacionados por comporem sistemas de produção alternativos à agricultura convencional.

No Brasil, como medida protetiva aos produtores e consumidores, esses produtos devem ser certificados pelo Sistema Brasileiro de Avaliação da Conformidade Orgânica, o qual estabelece três formas de certificação: por Sistema Participativo de Garantia, por Organização de Controle Social e por Auditoria., ${ }^{5,6}$ Por outro lado, a Lei ${ }^{0} 11.947 / 2009$, que regulamenta o Programa Nacional de Alimentação Escolar (PNAE), determina que no mínimo 30\% dos recursos repassados pelo 
Fundo Nacional de Desenvolvimento da Educação devem ser destinados à compra de alimentos produzidos pela agricultura familiar (local, regional ou nacional), ${ }^{7}$ podendo-se dispensar o processo licitatório e realizar a compra através da chamada pública, que possui legislação específica. ${ }^{8}$ Além disso, a Lei dispõe que os alimentos orgânicos e/ou agroecológicos estão entre as prioridades na compra, ${ }^{7}$ e poderão ter um acréscimo de até $30 \%$ em relação aos preços estabelecidos para produtos convencionais, na impossibilidade de realização de pesquisa de preços específica para esses produtos. ${ }^{7,8}$

Mesmo considerando leis e decretos de incentivo à aquisição de alimentos não convencionais, há sete anos o Brasil ocupa o lugar de maior consumidor de agrotóxicos do mundo e aumentou a compra de insumos agrícolas em 190\% na última década. A Associação Brasileira de Saúde Coletiva publicou o dossiê "Um alerta sobre os impactos dos agrotóxicos na saúde” em 2015, no qual relacionou a produção, exposição e consumo de alimentos convencionais, assim como o consumo de água contaminada por agrotóxicos a intoxicações agudas e crônicas, ocorrência de neoplasias, má formação, neuropatias, imunotoxicidade, alterações endócrinas, alterações do sistema reprodutor, do desenvolvimento e do crescimento. ${ }^{9}$ Por esse motivo, o consumo de alimentos orgânicos e/ou agroecológicos deve ser estimulado e é definido como uma prática alimentar saudável.2,10

A aquisição de alimentos provindos da agricultura familiar promove o aumento da variedade e inclusão de alimentos in natura ou minimamente processados na alimentação escolar, os quais promovem a formação de hábitos alimentares saudáveis. ${ }^{11,12} \mathrm{O}$ consumo de produtos orgânicos e/ou agroecológicos tem sido descrito como uma prática alimentar saudável, ${ }^{10}$ conceito este que converge com a premissa central do PNAE, que é contribuir para o crescimento, o desenvolvimento, a aprendizagem, o rendimento escolar dos estudantes e a formação de hábitos alimentares saudáveis. ${ }^{13}$ As diretrizes do PNAE incentivam o emprego de alimentos orgânicos e/ou agroecológicos como ações de promoção e implementação da Segurança Alimentar e Nutricional e do Direito Humano à Alimentação Adequada. ${ }^{14}$ Nessa perspectiva, este estudo objetivou descrever a aquisição de alimentos orgânicos e/ou agroecológicos para o Programa Nacional de Alimentação Escolar nos municípios do estado do Rio Grande do Sul (RS).

\section{Metodologia}

O presente estudo, de caráter transversal, integrou o Projeto de Pesquisa "O processo de compra e venda de gêneros alimentícios da agricultura familiar para a alimentação escolar no estado do Rio Grande do Sul”, desenvolvido em parceria com o Centro Colaborador em Alimentação e Nutrição do Escolar do Estado do Rio Grande do Sul.

Todos os municípios do RS $(\mathrm{n}=497)$ foram convidados a responder um questionário online utilizando o software SurveyMonkey ${ }^{\circledR}$, enviado para o endereço eletrônico da Secretaria Municipal de Educação. O convite foi direcionado aos representantes dessa Secretaria que participavam 
ativamente do processo de compra da agricultura familiar, como secretário de Educação, nutricionista responsável técnico ou representante da gestão municipal.

O questionário em formato eletrônico foi encaminhado juntamente com uma carta de apresentação, a qual descrevia os objetivos da pesquisa. Em dois momentos houve o reenvio do questionário a todos responsáveis que não retornaram a solicitação, assim como o contato via telefone para esclarecimento de dúvidas e verificação de recebimento. O retorno do questionário eletrônico preenchido serviu como concordância de participação e os municípios que expressaram recusa não foram novamente contatados.

Do questionário constavam 35 questões relacionadas à compra da agricultura familiar, elaboradas com base na legislação vigente, ${ }^{7,8,15}$ incluindo perguntas reativas a forma de aquisição, recursos utilizados, produtos adquiridos, entre outras. Para analisar a compra de produtos orgânicos e/ou agroecológicos provenientes da agricultura familiar, foram selecionadas as cinco questões específicas a seguir, sobre esta temática:

Questões do tipo Caixas de Seleção (pergunta simples que possibilitava que os respondentes selecionassem várias respostas em uma lista definida de opções, além da opção para descrição aberta "Outro", caso o respondente achasse necessário utilizá-la):

- Em 2014, foram comprados produtos ORGÂNICOS E/OU AGROECOLÓGICOS?

- Independentemente de o município adquirir ou não produtos ORGÂNICOS E/OU AGROECOLÓGICOS, qual(is) a(s) principal(is) dificuldade(s) na aquisição dos mesmos?

- Se o município adquiriu produtos ORGÂNICOS E/OU AGROECOLÓGICOS em 2014, o que influenciou esta escolha?

- Caso o município tenha comprado produtos ORGÂNICOS E/OU AGROECOLÓGICOS em 2014, estes produtos tinham certificação?

Questão do tipo caixa de comentários (permitia coletar respostas discursiva abertas longas)

- Caso o município tenha comprado produtos ORGÂNICOS E/OU AGROECOLÓGICOS em 2014, cite quais (especificando nos grupos alimentares: 1 - hortaliças, legumes e verduras, 2 frutas, 3 - bebidas 4 - cereais, pães, massas e tubérculos, 5 - carnes, pescados e ovos, 6 - leites e derivados (iogurte, bebida láctea, queijo, etc.), 7 - leguminosas (feijão, lentilha, grão de bico, soja, etc.), 8 - gorduras e óleos (banha de porco, azeite, etc.) e 9 - açúcares e doces.

Para a distribuição geográfica dos municípios participantes, os mesmos foram divididos em sete mesorregiões, segundo o Instituto Brasileiro de Geografia e Estatística: Nordeste Rio-grandense, Noroeste Rio-grandense, Centro Ocidental Rio-grandense, Centro Oriental Rio-grandense, Metropolitana de Porto Alegre, Sudoeste Rio-grandense e Sudeste Rio-grandense. ${ }^{16}$ 
A coleta dos dados foi realizada de agosto a outubro de 2015. Os dados extraídos da ferramenta eletrônica foram tabulados no software Excel $^{\circledR}$ versão 2013 e analisados de forma descritiva, por meio de frequências absolutas e relativas, mediana, número máximo e mínimo de produtos adquiridos por município.

A pesquisa foi aprovada pela Comissão de Pesquisa da Faculdade de Medicina da Universidade Federal do Rio Grande do Sul (Protocolo no 27.815).

\section{Resultados}

Dos 497 municípios pertencentes ao estado do RS, 371 participaram da pesquisa. Para as análises constantes no presente trabalho, foram utilizadas as $362(72,8 \%)$ respostas daqueles que completaram as questões que se referem à compra de alimentos de base agroecológica/orgânica.

Quando questionados sobre a compra de produtos orgânicos/agroecológicos no ano de 2014, 94 municípios (26,0\% dos que responderam à pesquisa e 18,9\% dos municípios do estado) afirmaram que adquiriram esse tipo de alimento. Ainda, dos 362 que responderam, 84 municípios (23,2\%) relataram que não compraram por problemas com documentação e certificação e 201 (55,5\%) por inexistência de produtores orgânicos interessados em fornecer para o Programa. Outros motivos foram relatados por dois municípios $(0,6 \%)$.

Em relação à distribuição geográfica, a taxa de respondentes com relação ao número de municípios que compõem cada mesorregião foi de 84,6\% (n=22/26) para a Região Sudeste; 79,6\% (n=43/54) para a Centro-Oriental; $75,9 \%(\mathrm{n}=41 / 54)$ para a Nordeste; $74,7 \%(\mathrm{n}=162 / 217)$ para a Noroeste; $66,3 \%(\mathrm{n}=65 / 98)$ para a Metropolitana de Porto Alegre; $64,5 \%(\mathrm{n}=20 / 31)$ para a Centro-Ocidental; e 52,9\% (n=9/17) para a Sudoeste. Respectivamente, para essas mesorregiões, 6, 14, 19, 21, 31, 1 e 2 municípios responderam afirmativamente que adquiriam produtos orgânicos e/ou agroecológicos, o que representa 27,3\%; 32,6\%; 46,3\%; 13,0\%; 47,7\%; 5,0\% e 22,2\% do total de municípios que compõem a região e que responderam à pesquisa. Contudo, se analisarmos o número total de respostas $(\mathrm{n}=362) \mathrm{e}$ compararmos em cada uma das mesorregiões, nota-se que a maior parte das respostas foi da Noroeste, com 44,8\% (n=162), o que se justifica por ser a mesorregião com o maior número de municípios (n=217) do RS, seguida da Metropolitana de Porto Alegre (18,0\%), Centro-Oriental (11,9\%), Nordeste (11,3\%), Sudeste $(6,1 \%)$ e Centro-Ocidental (5,5\%). Já a mesorregião com a menor porcentagem de respostas, a Sudoeste, com 2,5\% (n=9), é composta pelor menor número de municípios $(\mathrm{n}=17)$.

As principais dificuldades apontadas para a compra dos alimentos orgânicos e/ou agroecológicos dentre os municípios participantes $(n=362)$ e dentre aqueles que adquirem esses produtos $(n=94)$ estão apresentadas na tabela 1. Os entraves são semelhantes comparando-se os grupos, sendo que encontrar quantidade e variedade suficiente destes alimentos no mercado são os mais citados (acima de $46 \%$ dos municípios). 
Demetra: alimentaÇão, NUTRição \& Saúde

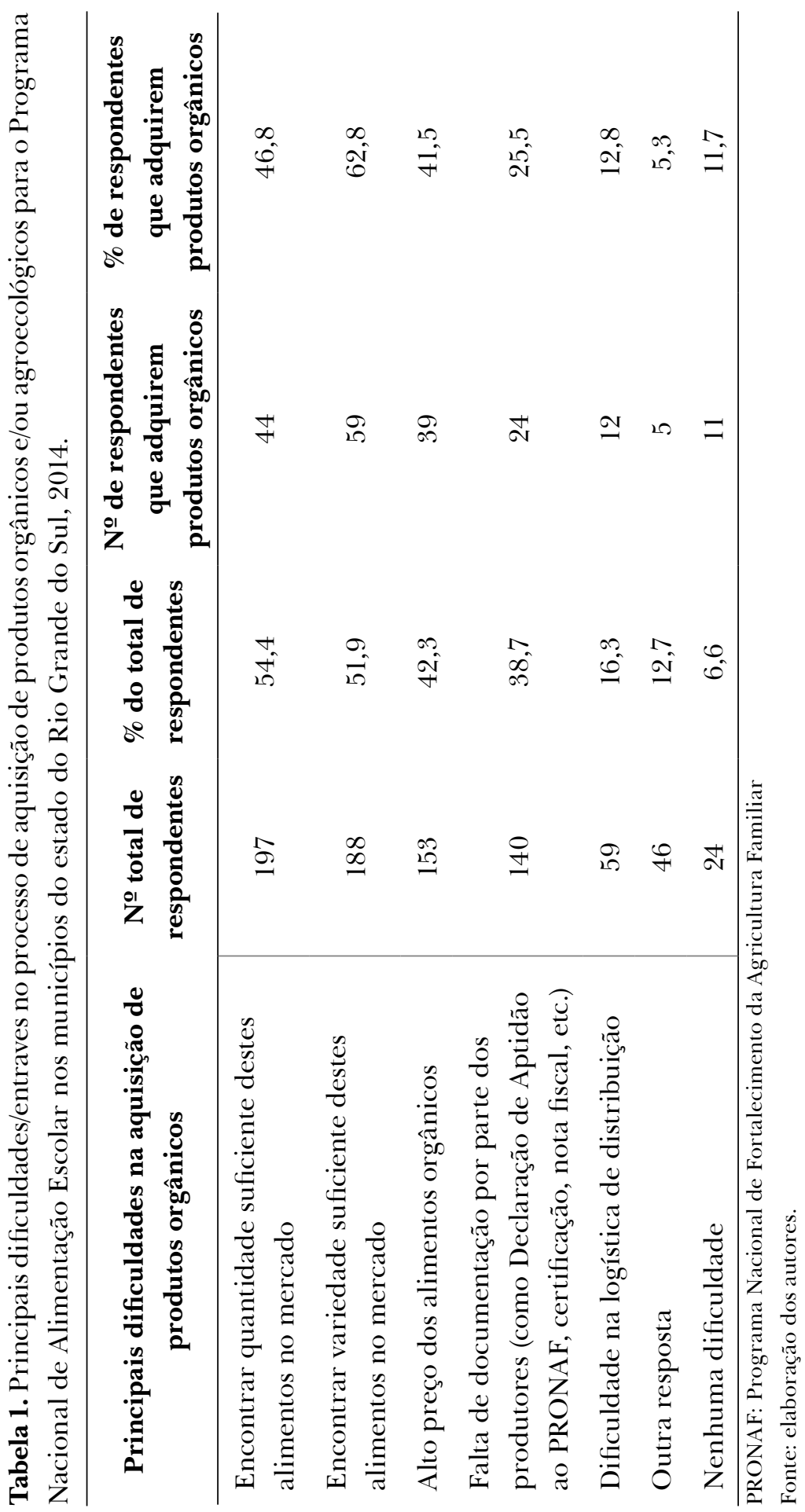


Apesar de os municípios (n=94) afirmarem que compram produtos de origem orgânica e/ ou agroecológica, 23,4\% (n=22) relataram que os produtos adquiridos não tinham certificação e $37,2 \%$ ( $n=35)$ referiram não conhecer o tipo de certificação que tinham. A forma de certificação mais citada pelos que sabiam foi por sistemas participativos por organização de controle social $(18,1 \% ; n=17)$, conforme a tabela 2 .

Tabela 2. Certificação e motivos para a compra de produtos orgânicos e/ou agroecológicos pelos municípios do estado do Rio Grande do Sul para o Programa Nacional de Alimentação Escolar, 2014.

\begin{tabular}{l|cc}
\hline Certificação dos produtos adquiridos pelos municípios & N & \% \\
\hline Certificação desconhecida & 35 & 37,2 \\
Sem certificação & 22 & 23,4 \\
Sistemas participativos por organização de controle social & 17 & 18,1 \\
Sistemas participativos de garantia & 15 & 16,0 \\
Auditoria & 5 & 5,3 \\
Não respondeu & 1 & 1,1 \\
\hline Principais motivos para aquisição & $\mathbf{N}$ & $\%$ \\
\hline Preocupação com a saúde da população assistida pelo & 87 & 92,6 \\
Programa Nacional de Alimentação Escolar & 81 & 86,2 \\
Formação de hábito saudável & 70 & 74,5 \\
Solicitação do nutricionista & 62 & 66,0 \\
Proteção ao meio ambiente & 57 & 60,6 \\
Maior conscientização ambiental & 49 & 52,1 \\
Interesse em estimular a economia local & 42 & 44,7 \\
Incentivo à permanência no campo & 37 & 39,4 \\
Incentivo do município & 34 & 36,2 \\
Melhorar a saúde dos agricultores & 26 & 27,7 \\
Garantia de venda da produção & 7 & 7,4 \\
Preço competitivo & 2 & 2,1 \\
Outra resposta & & \\
\hline
\end{tabular}

Fonte: elaboração dos autores. 
A tabela 2 também apresenta os principais motivos para a escolha desses produtos pelos municípios que os adquiriram. O principal fator que influencia a compra foi a preocupação com a saúde dos escolares assistidos pelo PNAE (92,6\%; n=87). Outras razões frequentemente citadas se resumem a dois motivos centrais, a saúde e o meio ambiente: preocupação com a formação de hábitos saudáveis $(86,2 \% ; \mathrm{n}=81)$, solicitação por parte do nutricionista $(74,5 \% ; \mathrm{n}=70)$; proteção do meio ambiente $(66,0 \% ; n=62)$ e a maior conscientização ambiental $(60,6 ; n=57)$.

Sobre a variedade dos alimentos, apenas quatro municípios não descreveram os produtos. As hortaliças foram as mais citadas $(55,3 \%$; $=52)$, com relato de 31 variedades no item "hortaliças, legumes e verduras". Os produtos mais comercializados nesse grupo foram: alface, repolho, cenoura, brócolis e beterraba. No grupo das frutas, as mais citadas foram: laranja, bergamota e morango, e o suco de uva foi apontado por 24,5\% dos municípios. Outros alimentos bastante citados foram o arroz e a mandioca, couve, tempero verde e feijão. O grupo das carnes e o grupo dos leites foram citados por apenas 5,3\% dos municípios, e o grupo das gorduras e óleos foi o único a não ter relatos de compra de orgânicos e/ou agroecológicos (tabela 3). O número máximo de alimentos adquiridos por um município foi de 55, e o mínimo, um; a mediana de produtos adquiridos foi de quatro (P25-P75). 


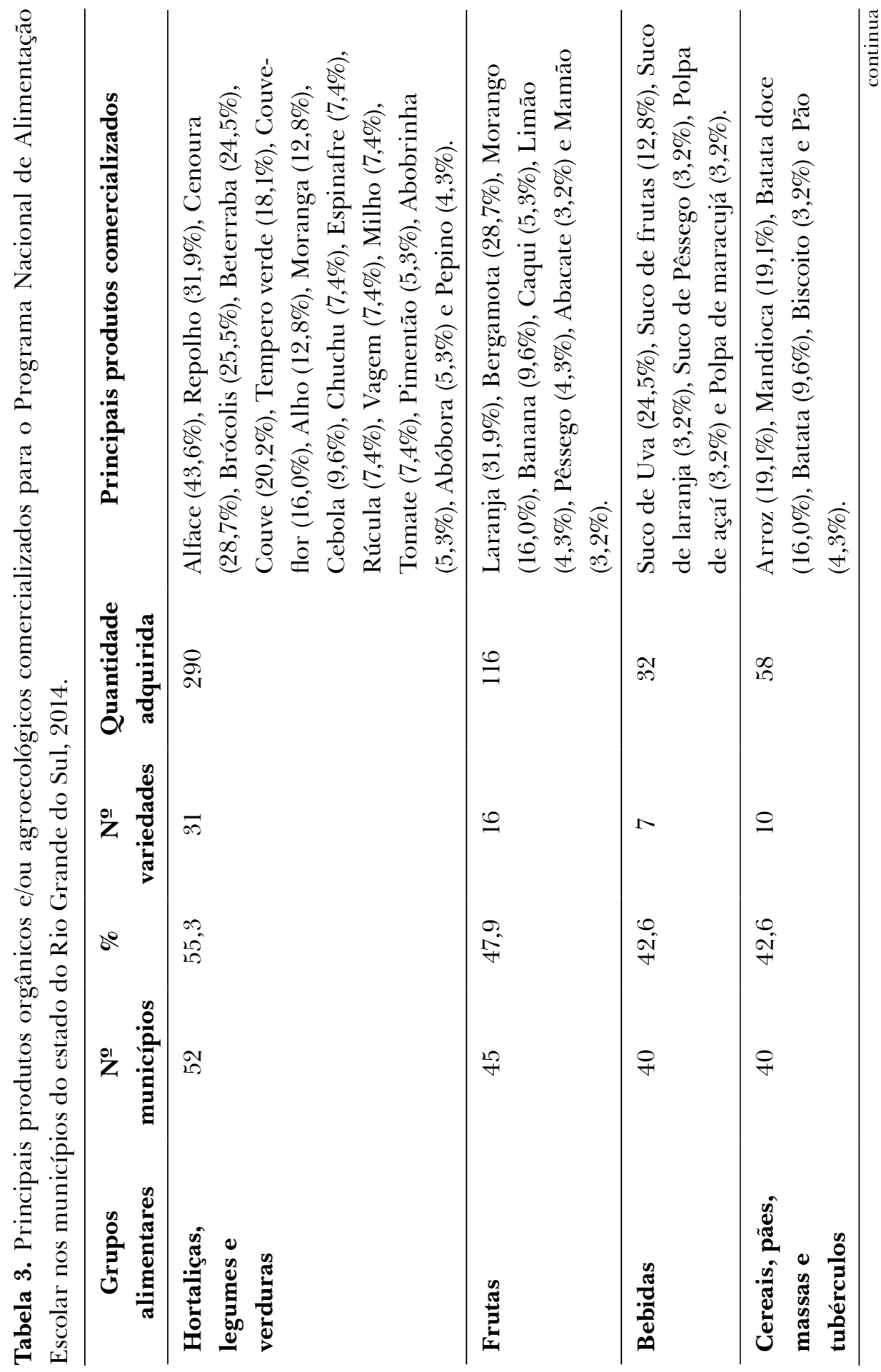




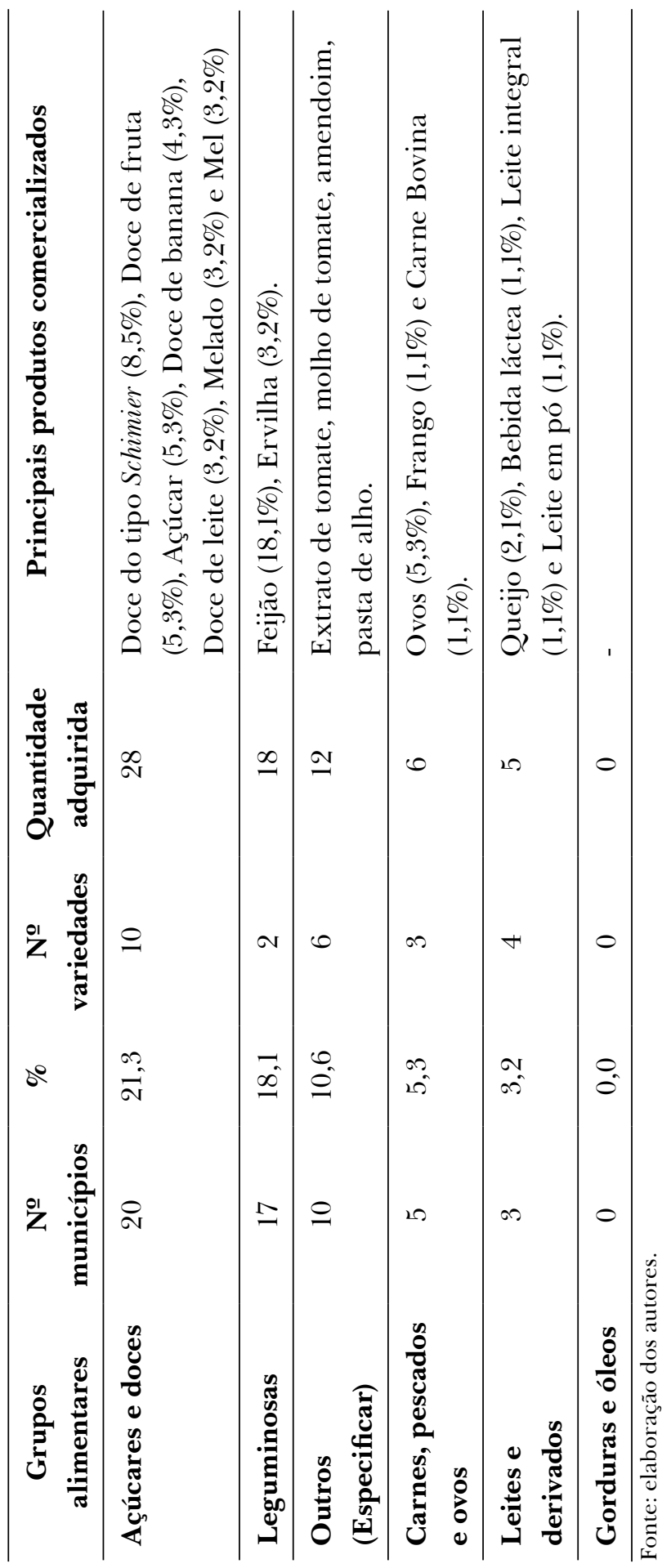




\section{Discussão}

Os resultados do presente estudo revelam que alguns municípios do RS adquirem produtos orgânicos e/ou agroecológicos, em conformidade com a Lei nº 11.947/2009. . Comparando-se essa aquisição entre Rio Grande do Sul e Santa Catarina, verifica-se que há semelhança entre os dois estados. Conforme dados do estudo de Silva e Souza, de 2005, 17,7\% (n=52) dos municípios de Santa Catarina adquiriam produtos orgânicos, ao passo que este percentual é de 18,9\% (n=94) no RS, conforme os dados aqui apresentados. ${ }^{17}$

No Cadastro Nacional de Produtores Orgânicos, estão registrados 1.662 produtores orgânicos no RS. A maioria (51,4\%; $n=855)$ está localizada na mesorregião Metropolitana de Porto Alegre, o que poderia justificar que 33,0\% das respostas afirmativas sobre a compra de produtos orgânicos e/ou agroecológicos foram relativas a essa região. ${ }^{18}$ A mesorregião Centro-Ocidental Rio-grandense apresenta o menor número de produtores nesse mesmo Cadastro $(1,0 \%$; $n=16)$; por conseguinte, foi a mesorregião neste estudo onde somente um município realizou a compra de alimentos orgânicos e/ou agroecológicos para o PNAE.

As maiores dificuldades apontadas pelos municípios respondentes foram a quantidade $(54,4 \%)$ e a variedade $(51,9 \%)$ disponíveis no mercado. Segundo a investigação realizada pelo Censo do Instituto Brasileiro de Geografia e Estatística em 2006, a produção orgânica no Brasil é baixa, representando apenas $1,8 \%$ do total. ${ }^{19}$ Contudo, apresentou crescimento em 2013, quando o número de unidades produtivas teve aumento de $22 \%$ em relação ao ano anterior. A Região Sul se destacou como a segunda maior em número de estabelecimentos e a quinta em área da agricultura familiar no Brasil..$^{20}$

$\mathrm{O}$ alto preço dos alimentos orgânicos e/ou agroecológicos também se destacou dentre as dificuldades, ocupando o terceiro lugar (42,3\%). O dossiê da Associação Brasileira de Saúde Coletiva também vinculou o preço como o principal entrave, assim como outros estudos relacionaram o alto preço à baixa capacidade de produção, ao difícil controle de pragas e às adversidades climáticas enfrentadas pelos produtores de alimentos orgânicos e/ou agroecológicos. ${ }^{9,21,22}$ Ademais, o gasto com transporte e o elevado custo da certificação reforçam os dados encontrados por estudos realizados nos estados de São Paulo e Santa Catarina. ${ }^{17,23}$ Pesquisas apontam que investimentos na produção orgânica, como, por exemplo, apoio técnico e capacitação das pessoas envolvidas no processo, poderiam reduzir os valores desses produtos. ${ }^{22}$

A obrigatoriedade da certificação orgânica possibilita maior credibilidade dos consumidores e maior transparência das práticas e dos princípios utilizados na produção. ${ }^{5,22}$ No entanto, os custos de certificação e as dificuldades no processo de sua implementação são indicados como os maiores responsáveis pelo baixo número de agricultores no Cadastro Nacional de Produtos Orgânicos. ${ }^{24}$ Logo, essas barreiras diminuem a disponibilidade de alimentos regularizados 
(certificados) para posterior comercialização em programas como o PNAE.$^{25}$ Os problemas com documentação e certificação foram apontados por 38,7\% dos municípios respondentes como razões para não aquisição de alimentos orgânicos e/ou agroecológicos, inclusive por 25,5\% dos municípios que já realizam a compra. Dados equivalentes foram relatados por Silva ${ }^{17}$ no estado de Santa Catarina: dos agricultores pesquisados, 66,7\% (n=64) não possuíam certificação, contra $11,5 \%(\mathrm{n}=11)$ que eram certificados ${ }^{17}$ Quanto ao tipo de certificação no RS, $18,1 \%$ dos produtos tinham certificação de Organização por Controle Social, que é possível quando há venda direta ao consumidor (neste caso, o PNAE), sem a necessidade de certificação, sendo a garantia atestada por uma organização previamente cadastrada junto a órgão fiscalizador. ${ }^{5}$ Já o Sistema Participativo de Garantia, formado por produtores, consumidores, técnicos e pesquisadores que se autocertificam, foi relatado por 16,0\% dos municípios; e a Auditoria, cuja certificação é dada por uma instituição que inspeciona as condições técnicas, sociais e ambientais da produção e verifica se estão de acordo com as exigências dos regulamentos da produção orgânica, por somente 5,3\%. ${ }^{5}$ Segundo o Banco Nacional de Desenvolvimento, ${ }^{22}$ a "Certificação Participativa" foi desenvolvida para tornar acessível a regulamentação dos produtores com pouca disponibilidade financeira, o que se reproduz em estudos que mostram esse tipo de certificação como a mais prevalente. ${ }^{17,26}$

Os principais fatores apontados neste estudo como influência para a compra de alimentos orgânicos e/ou agroecológicos foram a preocupação com a saúde e a formação de hábito saudável da população assistida pelo PNAE, o que reflete o conhecimento da relação desses alimentos com a saúde, pelos gestores municipais.

Os gêneros alimentícios orgânicos e/ou agroecológicos mais adquiridos pelos municípios do RS foram hortaliças e frutas, com destaque para alface, repolho, laranja, bergamota e cenoura. Segundo o Programa de Análise de Resíduos de Agrotóxicos em Alimentos da Agência Nacional de Vigilância Sanitária, alimentos como alface e laranja, quando produzidos pela agricultura convencional, apresentaram altos índices de contaminação por agrotóxicos (aproximadamente 50\% dessas amostras coletadas em 26 estados brasileiros apresentavam contaminação por ingredientes ativos não autorizados ou acima do limite de autorização). ${ }^{27}$ Assim, a aquisição desses produtos é um ponto relevante para a diminuição do consumo de agrotóxicos pelos escolares atendidos pelo PNAE.

\section{Considerações finais}

A agricultura orgânica e/ou agroecológica tem por objetivo a qualidade de vida e a saúde não só para o produtor, como também para o consumidor. A inclusão de alimentos seguros, livres de contaminantes e variados na alimentação escolar através do PNAE promove a Segurança Alimentar e Nutricional da população escolar e atua como veículo de geração de renda às famílias 
produtoras, que encontram no Programa uma demanda de mercado. Por conseguinte, a aliança entre a produção orgânica e o PNAE promove saúde, renda e qualidade de vida para todos os envolvidos nesse processo.

Neste estudo pode-se constatar que as entidades executoras estão adotando, paulatinamente, as leis e regulamentações que estimulam a aquisição de alimentos orgânicos e/ou agroecológicos. Observa-se também a preocupação em relação à saúde e ao meio ambiente. Entretanto, analisando os resultados, percebe-se que a demanda e a oferta desses produtos estão desequilibradas, o que reflete a necessidade de fomentar a articulação entre responsáveis técnicos, agricultores familiares e demais atores participantes do processo de aquisição para a alimentação escolar e a permanência dos incentivos governamentais.

\section{Colaboradores}

Machado LS foi responsável pela coleta, concepção e análise dos dados, revisão bibliográfica e redação do artigo. Rockett FC participou da elaboração do projeto, coleta, análise e interpretação dos dados, redação e revisão do manuscrito. Pires GC, Corrêa RS e Oliveira ABA participaram da concepção do estudo, coleta de dados e revisão do manuscrito. Todos os autores aprovaram a versão final do manuscrito.

Conflito de interesses: as autoras declaram não haver conflito de interesses.

\section{Referências}

1. Food and Agriculture Organization. Organic agriculture. Rome: FAO; 1999.

2. Brasil. Ministério da Saúde. Guia alimentar para a população brasileira. Brasília: Ministério da Saúde; 2014.

3. Souza AA, Santos PCT, Bezerra OMPA. Agroecologia [Internet]. Espírito Santo: CECANE; Minas Gerais: UFOP; 2012. [acesso em: 9 nov. 2015]. Disponível em: http://www.unifesp.br/campus/san7/ images/cecane/agroecologia.pdf

4. Carneiro JJ, Cardoso IM, Moreira VDL. Agroecologia e conservação de água: um estudo de caso no município de Araponga. Rev Bras Agroec. 2009; 4(2):378-382.

5. Brasil. Decreto ${ }^{\circ}$ 6.323, de 27 de dezembro de 2007. Regulamenta a Lei no 10.831, de 23 de dezembro de 2003, que dispõe sobre a agricultura orgânica, e dá outras providências. Diário Oficial da União. 27 dez. 2009.

6. Brasil. Ministério da Agricultura, Pecuária e Abastecimento. Regularização da Produção Orgânica. Brasília: MAPA; 2015. 
7. Brasil. Lei no 11.947, de 16 de Junho de 2009. Dispõe sobre o atendimento da alimentação escolar e do Programa Dinheiro Direto na Escola aos alunos da educação básica; altera as Leis nos 10.880, de 9 de junho de 2004, 11.273, de 6 de fevereiro de 2006, 11.507, de 20 de julho de 2007; revoga dispositivos da Medida Provisória no 2.178-36, de 24 de agosto de 2001, e a Lei no 8.913, de 12 de julho de 1994; e dá outras providências. Diário Oficial da União. 16 jun. 2009.

8. Brasil. Resolução no 04, de 2 de Abril de 2015. Altera a redação dos artigos 25 a 32 da Resolução/ CD/FNDE no 26, de 17 de junho de 2013, no âmbito do Programa Nacional de Alimentação Escolar (PNAE). Diário Oficial da União. 2 abr. 2015.

9. Associação Brasileira de Saúde Coletiva. Dossiê ABRASCO, Um alerta sobre o impacto dos Agrotóxicos na Saúde. Parte 1- Agrotóxicos, Segurança Alimentar e Saúde. Rio de Janeiro: ABRASCO; 2015.

10. International Federation of Organic Agriculture Movements. Definition of organic agriculture. Itália: IFOAM; 2008.

11. Triches RM, Schneider S. Alimentação escolar e agricultura familiar: reconectando o consumo à produção. Saúde Soc. 2010; 19(4):933-945.

12. Schmitt CJ, Guimarães LA. O mercado institucional como instrumento para fortalecimento da agricultura familiar de base ecológica. Agriculturas. 2008; 5(2):7.

13. Brasil. Ministério da Educação. Cartilha Nacional da Alimentação Escolar. 2 ed. Brasília: Ministério da Educação; 2015.

14. Ação Brasileira pela Nutrição e Direitos Humanos. Direito Humano à Alimentação Adequada no Contexto da Segurança Alimentar e Nutricional. Brasília: ABRANDH; 2010.

15. Brasil. Resolução no 26, de 17 de Junho de 2013. Dispõe sobre o atendimento da alimentação escolar aos alunos da educação básica no âmbito do Programa Nacional de Alimentação Escolar - PNAE. Diário Oficial da União.13 jun. 2013.

16. Instituto Brasileiro de Geografia e Estatística. Censo Demográfico 2010. Rio de Janeiro: IBGE; 2010.

17. Silva APF, Souza AA. Alimentos orgânicos da agricultura familiar no Programa Nacional de alimentação Escolar do Estado de Santa Catarina, Brasil. Rev Nutr. 2005; 26(6):701-714.

18. Brasil. Ministério da agricultura, Pecuária e abastecimento. Cadastro Nacional de Produtores Orgânicos. Brasília: MAPA; 2015. [Acesso em: 24 jun. 2017]. Disponível em: http://www.agricultura. gov.br/assuntos/sustentabilidade/organicos/cadastro-nacional-produtores-organicos

19. Instituto Brasileiro de Geografia e Estatística. Censo agropecuário 2006. Rio de Janeiro: IBGE; 2009.

20. Brasil. Ministério da Agricultura, Pecuária e Abastecimento. Aumenta o número de produtores de orgânicos no Brasil [Internet]. [acesso em: 09 nov. 2015]. Disponível em: http://planetaorganico.com. br/site/index.php/prodorg-no-brasil/

21. Souza LBB. Organizações da agricultura familiar no Estado de São Paulo e sua experiência de fornecimento para o PNAE. Projeto Nutre SP: análise da inclusão da agricultura familiar na alimentação escolar no Estado de São Paulo. Brasília: Ministério do Desenvolvimento Agrário; 2012.

22. Ormond PJ, Paula SRL, Faveret Filho PSC, Rocha LTM. Agricultura orgânica: quando o passado é futuro. BNDES Setorial. 2002; (15):3-34. 
23. Lima EE, Sousa AA. Alimentos orgânicos na produção de refeições escolares: limites e possibilidades em uma escola pública em Florianópolis. Rev. Nutr. 2011; 24(2):263-273.

24. Altmann R, Oltramari AC. A agricultura orgânica na região da Grande Florianópolis: indicadores de desenvolvimento. Florianópolis: Instituto CEPA/SC; 2004.

25. Anjos FS, Caldas NV, Trentin IL. Desafios e possibilidades: certificação social e solidária no contexto da agricultura familiar. Organ Rurais Agroind. 2006; (3):334-343.

26. Santos F, Fernandes PF, Rockett FC, Oliveira ABA. Avaliação da inserção de alimentos orgânicos provenientes da agricultura familiar na alimentação escolar, em municípios dos territórios rurais do Rio Grande do Sul, Brasil. Ciênc Saúde Coletiva. 2012; 19(5):1429-1436.

27. Brasil. Agência Nacional de Vigilância Sanitária. Programa de Análise de Resíduo de Agrotóxico em Alimentos (PARA). Relatório de atividades de 2011 e 2012. Brasília: ANVISA; 2013.

Recebido: 04 de outubro, 2017

Revisado: 01 de fevereiro, 2018

Aceito: 05 de março, 2018 
